\title{
SELECTED RISK FACTORS FOR CERVICAL CANCER AND BARRIERS TO CERVICAL CANCER SCREENING
}

\author{
Szaboova V, Svihrova V, Hudeckova V.
}

Department of Public Health, Jessenius Faculty of Medicine in Martin, Comenius University in Bratislava, Slovak Republic

\begin{abstract}
A b s t r a c t
The article provides a review of literature on risk factors and cofactors for cervical cancer and barriers to cervical cancer screening. Cofactors of cervical cancer are risk factors that contribute to the development of cervical cancer but are not able to generate cancer on their own. Risk factors and cofactors of cervical cancer have been clearly identified in many studies. Therefore cervical cancer is a preventable type of cancer. The aim of this article was to describe in more detail the barriers to cervical cancer screening among women all over the world. The barriers to cervical cancer screening can be sorted according to the results of studies into five main groups: informational, psychological, socio-economic, behavioral and cultural, and geographical. Efforts to reduce risk factors and cofactors of HPV infection and cervical cancer and to increase knowledge about screening are necessary in a positive approach to preventing cervical cancer in society and to promote women's health.
\end{abstract}

Key words: cervical cancer, barriers to screening, risk factors and cofactors, screening

\section{INTRODUCTION}

High-risk human papillomaviruses (HPVs), especially types 16 and 18, are main etiological factors of cervical cancer. Risk factors related to the acquisition of HPV infection have been clearly identified. A close and direct relation of persistent HPV infection in cervical epithelium to the development of cervical intraepithelial neoplasia (CIN) was confirmed in many studies $(1,2)$. Cofactors of cervical cancer are risk factors that contribute to the development of cervical cancer but are not able to generate cancer on their own. Risk factors and cofactors of cervical cancer have been clearly identified in many studies $(3,4)$. Therefore cervical cancer is a preventable type of cancer. Primary prevention is represented by vaccination against HPV infection. Screening is used as a means of secondary prevention all over the world. Women of every age need to participate in cervical cancer screening programs. Many countries have a problem with women's low interest in participating in screening programs. Regional differences in cervical cancer screening participation are determined by different factors. Only 18 to $20 \%$ of Slovak women participate in preventive gynecologic examinations (5). This results in low participation in cervical cancer screening, which is a part of preventive gynecologic examinations. The fact that women in Slovakia are not invited to the cervical cancer screening can be an important factor in their decisions about attendance in screening programs.

Higher participation in cervical cancer screening results in lower cervical cancer incidence, prevalence, and mortality rates. This result can be seen in north European countries where approximately $80 \%$ of women participate in cervical cancer screening progams. Finland is an example of country where cervical cancer screening is population-based and women are invited to the examinations. Screening participation in Finland is at $70 \%$ (6). In countries of Central and Eastern Europe, the lower participation results in higher incidence

Corresponding a u thor:

Veronika Szabóová, MD, Department of Public Health, Jessenius Faculty of Medicine in Martin, Comenius University in Bratislava, Sklabinská Str. N. 26, 03601 Martin, Slovak Republic

e-mail: publichealth.veronica@gmail.com 
of and mortality rates due to cervical cancer. For this reason, focusing attention on promoting cervical cancer screening participation is very important. Table 1 shows incidence and mortality rates for cervical cancer in selected European counties (7).

Table 1 Cervical cancer incidence and mortality rates in selected European counties (7).

\begin{tabular}{|l|c|c|}
\hline Country & $\begin{array}{c}\text { Cervical cancer incidence rates } \\
\text { per 100.000 women per year }\end{array}$ & $\begin{array}{c}\text { Cervical cancer mortality } \\
\text { rates per 100.000 women } \\
\text { per year }\end{array}$ \\
\hline Czech Republic & 18.9 & 5.9 \\
\hline Denmark & 12.9 & 3.4 \\
\hline Finland & 5.2 & 1.9 \\
\hline France & 8.8 & 3.6 \\
\hline Germany & 12 & 3.8 \\
\hline Hungary & 22.5 & 8.8 \\
\hline Israel & 5.2 & 3.1 \\
\hline Italy & 9.4 & 3.3 \\
\hline Norway & 11.9 & 4.1 \\
\hline Slovakia & 21.6 & 8.2 \\
\hline
\end{tabular}

\section{Risk factors for HPV infection}

HPV infection is a precondition for the development of cervical cancer. Therefore risk factors for HPV infection are considered to also be the risk factors for cervical cancer. There are more factors and cofactors needed for the development of cervical cancer because HPV infection alone does not create the conditions for the development of neoplastic changes in the cervical epithelium $(3,8,9)$.

Risk factors of HPV infection and of cervical cancer are represented by risky sexual behaviors, including promiscuity, a high number of sexual partners, HPV-positive sexual partners, polygamy, and early onset of sexual behavior. A multicentric study from 11 countries of 4 different continents published in 2006 by the International Agency for Research on Cancer (IARC) aimed at acquiring statistically significant data about risk factors of HPV infection and cervical cancer (4). Higher number of sexual partners (more than 4) proved to be the most important risk factor. Another studies confirmed that the risk of HPV infection persistence, the development of CIN lesions, and cervical cancer increase with the number of sexual partners (10). Early onset of sexual activity, i.e. in girls younger than 16, is also one of the most significant risk factors for HPV infection (11). Risky sexual behavior is defined as a risk factor for cervical cancer when it has a relationship to the acquisition of HPV infection. Other factors that could be included in risky sexual behavior, such as prolonged hormonal contraceptive use or sexually transmitted disease belong to cofactors of cervical cancer because they are not primarily associated with acquisition of HPV infection. They only contribute to the development of changes in cervical epithelium when HPV infection is present. 


\section{Risk factors for progression of HPV infection to higher stages of CIN and cervical cancer}

Different environmental and genetic factors are involved in the pogression of persistent infection into the development of cervical cancer. These factors, affecting the beginning of development of neoplastic changes in the epithelium of the cervix and coacting in the cervical cancer etiology, are termed cofactors of cervical carcinogenesis (3). Cofactors themselves do not cause the disease, but they are needed to maintain the persistence of infection in cervical epithelium.

Cofactors of cervical cancer include hormonal factors (prolonged hormonal contraceptive use, higher number of childbirths), smoking, immune system deficiency diseases (HIV infection, oncological diseases), another sexually transmitted diseases (herpes simplex virus type 2, Chlamydia trachomatis, HIV), nutrition and nutritional factors, chronic noncommunicable diseases and metabolic disorders, and the absence of cervical cytology screening. The importance of immune system status and immune response in relation to HPV viruses according to HPV genotype is scientifically proven $(3,8,9)$.

IARC divides the cofactors engaged in the development of cervical carcinogenesis into two groups: infectious (coinfection by other types of HPV, the presence of another sexually transmitted diasease) and noninfectious (all others mentioned, including risky sexual behavior) (2).

\section{Barriers to cervical cancer screening}

For a better understanding of barriers, it is important to first define the hard-to-reach populations. A hard-to-reach population is a population or community that is difficult to engage in public screening participation. It may be a minority group (e.g. ethnic group), a group of illegal immigrants, or groups "resistant" to health care services (they do not use services that are available). The reasons that certain groups are identified as hard to reach include different demographic, cultural, behavioral, relational and structural factors (5). There is no homogenity within the definition of hard-to-reach populations. Certain groups may be hard to reach in certain contexts or locations, but not in others. Prejudices against hard-to-reach groups and people might also emerge when only people with low socio-economic statuses are considered to be in this category. Inequalities in cervical cancer screening participation according to socio-economic status are higher in the countries without programs for screening oncologic diseases (12).

Problems with women's low participation in cervical cancer screening programs exist in both developing and in developed countries, including in Slovakia. Therefore numerous scientific studies all over the world have been conducted to define the reasons that women do not participate in cervical screening programs. The barriers to cervical cancer screening can be sorted according to the results of studies into five main groups: informational, psychological, socio-economic, behavioral and cultural, and geographical (13). The boundaries between the groups of barriers are blurred and overlap each other. Reasons that women do not participate in screening are subjective and therefore difficult to be clearly described and defined. Questionnaire methods of scientific work have been used to identify barriers in the studies (13).

Informational barriers occur in more areas. Many women do not have enough appropriate information regarding HPV infection, cofactors for CIN lesions and cervical cancer and about the danger and severity of disease $(14,15)$. On the other hand, other women miss information about cervical cancer prevention programs and the importance of screening $(16,17,18)$. Some women may not know that cervical cancer is a preventable disease, or they may know about the prevention but do not have access to health care facilities where they can be examined, and that is the reason they do not participate in screening programs $(18,19)$. Among those who participate in screening regularly, groups of working women with higher education and income were found to have higher levels of information about the prevention of the disease $(18,20)$. 
Psychological barriers were found to be based on the lack of knowledge about screening, fear of the examinations, fear of a positive test result, fear that the examination would be uncomfortable and painful, feelings of shame in front of the doctor, and a preference for women to perform the examination $(20,21,22,23)$. Distrust of health care professionals as a result of previous negative experiences were also found $(24,25)$. These barriers are primarily related to lower education and lower socio-economic status $(15,26)$.

Psychological barriers have also been observed in certain specific groups of women. Physical or mental disability (27), sexual abuse (28), belonging to groups of immigrants (26) or rural living (16) are barriers to screening based on predominantly psychological causes. These include fear of the examinations, shame, harm, and psychological blocks, and they occur due to lack of knowledge and a low awareness of the danger of cervical cancer and its prevention (23). Psychological barriers and fear of inappropriate comments by health care professionals were found in groups of women who are overweight or obese (29).

Several studies have found a link between low socio-economic status and a lack of knowledge about cervical cancer screening and low participation in screening programs. This link is probably caused by these women's limited access to information and to health care (19, 30 ). The link was found between the unwillingness of women from lower socio-economic levels of society to undergo screening and these women's lower interest to take care of their own health. Lower participation in cervical cancer screening programs was also found in groups of women with lower education, and these barriers are described as educational barriers to cervical cancer screening $(30,31)$. However, low cervical cancer screening participation of women with lower education is not a rule (26).

Women were found to be motivated to undergo cervical cancer screening by a sense of responsibility and a feeling of security that the disease can be diagnosed early and treated in a timely manner (32). Positive family history for cancer (23), early onset of sexual activity, and the use of hormonal contraceptives (22) have been found to be related with more frequent screening participation in regular intervals and willingness to cooperate with the health care system in the prevention of the disease (18). Cervical cancer screening participation of women with the above-mentioned characteristics is probably due to the higher interest in their own health and their healthy lifestyles compared to women from lower socio-economic levels of society $(23,32)$.

Age has not been found to be a crucial factor in screening participation because in both younger and older age groups of women, the same types of barriers were described (19). However, some studies mentioned an association between younger age and low participation in screening. This association was explained by the fact that younger women do not have enough knowledge about the meaning and the importance of screening, and they are not interested in prevention. They think that the disease is not a problem at their age. In some countries, they do not have the necessary health insurance (33).

In countries where no compulsory health insurance exists, women with health insurance, married women $(34,35)$, and women with sufficient knowledge about the Pap test and its importance are more likely to participate in screening $(22,23,35)$. Not having health insurance is also included in the barriers to cervical cancer screening related to socio-economic status $(17,33)$.

Behavioral and cultural barriers include the position of women in society and their affiliation with different ethnic and cultural groups (18). Women's attitudes toward cancer prevention were found to be shaped by the environment they live in and where they grew up $(24,34)$. Behavioral and cultural barriers to cervical cancer screening include feelings that they would be neglecting family responsibilities and child care at the time of visiting the doctor $(15,25)$ or the fear of the examination and feelings of shame $(36)$. Women in some cultural groups were discouraged from screening if the doctor was male and they were prejudiced to such examinations (26). Forgetting the term of screening appointments was also considered to be one of the behavioral barriers (36).

Geographical barriers to cervical cancer screening due to lack of access to health care facilities, centers, and health services performing the screenings, along with the long dis- 
tances and expensive transport, prevail, especially in developing countries (37). Problems with all the other groups of barriers, especially women's lack of awareness about the dangers of HPV infection and cervical cancer and the importance and availability of screening occur particularly in developing countries $(15,16,18)$. Increasingly, there are also psychological barriers and barriers resulting from low standards of living and low socio-economic status (31). Cultural and behavioral attitudes and habits are also a significant factor in access to screening as a result of many prejudices in certain societies and groups of women (26).

\section{Barriers to cervical cancer screening in Slovakia}

Cervical cancer screening in Slovakia is part of preventive gynecologic examination. In spite of the fact that it is covered by health insurance, only $18-20 \%$ of women participate in preventive gynecological examinations. Therefore it is necessary to increase women's participation in preventive examinations and to target the efforts to increase adherence to screening program among hard-to-reach groups. Low adherence to screening is usually connected to several reasons in the higher risks of developing cervical cancer. Women with low adherence are often diagnosed at an advanced stage of the disease. It is necessary to analyze the specific barriers that reduce adherence to preventive examinatins and cervical cancer screening among hard-to-reach populations. This is a prerequisite for the removal of the barriers $(5,38)$.

Barriers to cervical cancer screening have not yet been studied or described in Slovakia. We can assume the existence of particular socio-economic barriers, e.g. absence from work during the doctor visits contribute. Women may also have psychological barriers, fears, and worries because of the examination or the results of test (5).

\section{Conclusion}

Cervical cancer is a preventable disease and is relatively easy to diagnose. Low cervical cancer screening participation all over the world is associated with different barriers. Support for women by society and by health professionals in the case of risk factors, cofactors, and barriers to cervical cancer screening is an important part of public health practice. Efforts to reduce risk factors and cofactors of HPV infection and cervical cancer and to increase knowledge about screening are necessary in a positive approach to preventing cervical cancer in society and to promote women's health. There is a strong need to focus public health measures on the elimination of barriers to cervical cancer screening. Such measures would help to increase women's participation in preventive gynecological examinations, and thus cervical cancer screening.

\section{REFERENCES}

1. Bosch FX, Lorincz A, Muñoz N et al. The causal relation between human papillomavirus and cervical cancer. J Clin Pathol 2002; 55 (4): 244-65.

2. IARC. Human papillomaviruses. IARC Monographs on the Evaluation of Carcinogenic Risks to Humans: volume 90. Lyon: IARC Press; 2007. ISBN 978-92-832-1290-4.

3. Castellsagué X, Bosch FX, Muñoz N. Environmental co-factors in HPV carcinogenesis. Virus Res 2002; 89 (2): 191-9.

4. Vaccarella S, Franceschi S, Herrero R et al. Sexual behavior, condom use, and human papillomavirus: pooled analysis of the IARC human papillomavirus prevalence surveys. Cancer Epidemiol Biomarkers Prev 2006; 15 (2): 326-33.

5. Ilardi M, Shikova E et al. D3 - Analýza miestnych súvislostí [CD-ROM]. Projekt AURORA; 2012.

6. Institute for Statistical and Epidemiological Cancer Research: Finnish Cancer Registry [online]. 2010 [cit. 201408-12]. Available at: http://www.cancer.fi/syoparekisteri/en/mass-screening-registry/cervical_cancer_screening/improving-attendance-rates/

7. ICO Information Centre on HPV and Cancer: Data Query [online]. 2014 [cit. 2014-08-12]. Available at: http://www.hpvcentre.net/dataquery.php

8. Ulmer H, Bjørge T, Concin H et al. Metabolic risk factors and cervical cancer in the metabolic syndrome and cancer project (Me-Can). Gynecol Oncol 2012; 125 (2): 330-5.

9. Chelimo C, Wouldes TA, Cameron LD et al. Risk factors for and prevention of human papillomaviruses (HPV), genital warts and cervical cancer. J Infect 2013; 66 (3): 207-17. 
10. Luhn P, Walker J, Schiffman M et al. The role of co-factors in the progression from human papillomavirus infection to cervical cancer. Gynecol Oncol 2013; 128 (2): 265-70.

11. Plummer M, Peto J, Franceschi S et al. Time since first sexual intercourse and the risk of cervical cancer. Int J Cancer 2012; 130 (11): 2638-44.

12. Palència L, Espelt A, Rodríguez-Sanz M. et al. Socio-economic inequalities in breast and cervical cancer screening practices in Europe: influence of the type of screening program. Int $J$ Epidemiol 2010; 39 (3): 757-65.

13. Szabóová V, Švihrová V. Bariéry skríningu rakoviny krčka maternice u žien vo svete. In: 13. Červenkove dni preventivnej mediciny [CD-ROM]. Bratislava: SLS; 2014. p. 64.

14. Philips Z, Avis M, Whynes DK. Knowledge of cervical cancer and screening among women in east-central England. Int J Gynecol Cancer 2005; 15 (4): 639-45.

15. Fang DM, Baker DL. Barriers and facilitators of cervical cancer screening among women of Hmong origin. J Health Care Poor Underserved 2013; 24 (2): 540-55.

16. Fort VK, Makin MS, Siegler AJ et al. Barriers, to cervical cancer screening in Mulanje, Malawi: a qualitative study. Patient Prefer Adherence 2011; 5: 125-31.

17. Bakogianni GD, Goutsou SC, Liti MV et al. Knowledge, attitude, and practice of cervical cancer screening among Greek students: a short report. Int J Adolesc Med Health 2012; 24 (4): 329-30.

18. Yanikkerem E, Goker A, Piro N et al. Knowledge about cervical cancer, Pap test and barriers towards cervical screening of women in Turkey. J Cancer Educ 2013; 28 (2): 375-83.

19. Black AT, McCulloch A, Martin RE et al. Young women cervical cancer screening: what barriers persist? Can J Nurs Res 2011; 43 (1): 8-21.

20. Matejic B, Vukovic D, Pekmezovic T et al. Determinants of preventive health behavior in realtion to cervical cancer screening among the female population of Belgrade. Health Educ Res 2011; 26 (2): 201-11.

21. Waller J, Bartoszek M, Marlow L et al. Barriers to cervical cancer screening attendance in England: a population-based survey. J Med Screen 2009; 16 (4): 199-204.

22. Wall KM, Rocha GM, Slinas-Martinez AM et al. Modifiable barriers to cervical cancer screening adherence among working women in Mexico. J Womens Health 2010; 19 (7): 1263-70.

23. Jia Y, Li S, Yang R et al. Knowledge about cervical cancer and barriers of screening program among women in Wufeng country, a high-incidence region of cervical cancer in China. PLoS One 2013; 8 (7): e67005.

24. Abdullahi A, Copping J, Kessel A et al. Cervical screening: perceptions and barriers to uptake among Somali women in Camden. Public Health 2009; 123 (10): 680-5.

25. Giarelli E, Bruner DW, Nguyen E et al. Research participation among Asian American women at risk for cervical cancer: exploratory pilot of barriers and enhancers. J Immigr Minor Health 2011; 13 (6): 1055-68.

26. Augusto EF, Rosa ML, Cavalcanti SM et al. Barriers to cervical cancer screening in women attending the Family Medical Program in Niteroi, Rio de Janeiro. Arch Gynecol Obstet 2013; 287 (1): 53-8.

27. Wu LW, Lin LP, Chen SF et al. Knowledge and attitudes regarding cervical cancer sceening among women with physical diabilities living in the community. Res Dev Disabil 2012; 33 (2): 376-81.

28. Cadman L, Waller J, Ashdown-Barr L et al. Barriers to cervical screening in women who have experienced sexual abuse: an exploratory study. J Fam Plann Reprod Health Care 2012; 38 (4): 214-20.

29. Friedman AM, Hemler JR, Rossetti E et al. Obese women s barriers to mamography and pap smear: the possible role of personality. Obesity (Silver Spring) 2012; 20 (8): 1611-17.

30. Daley E, Alio A, Anstey EH et al. Examining barriers to cervical cancer screening and treatment in Florida through a socio-ecological lens. J Community Health 2011; 36 (1): 121-31.

31. Spadea T, Bellini S, Kunst A et al. The impact of interventions to improve attendance in female cancer screening among lower socioeconomic groups: a review. Prev Med 2010; 50 (4): 159-64.

32. Whynes DK, Philips Z, Avis M. Why do women participate in the English cervical cancer screening programme? $\mathrm{J}$ Health Econ 2007; 26 (2): 306-25.

33. Bang JY, Yadegarfar G, Soljak M et al. Primary care factors associated with cervical screening coverage in England. J Public Health (Oxf) 2012; 34 (4): 532-8.

34. Dimitrakaki C, Boulamatsis D, Mariolis A et al. Use of cancer services in Greece and associated social factors: results from the antion-wide Hellas Health I survey. Eur J Cancer Prev 2009; 18 (3): 248-57.

35. Paolino M, Arrossi S. Women s knowledge about cervical cancer, Pap smear and human papillomavirus and its relation to screening in Argentina. Women Health 2011; 51 (1): 72-87.

36. Rafael RdeM, Moura AT. Barriers to implementation of cervical cancer screening: a household survey in the coverage area of the Family Health Program in Nova Iguacu, Rio de Janeiro State, Brazil. Cad Saude Publica 2010; 26 (5): 1045-50.

37. World Health Organization. WHO guidance note: comprehensive cervical cancer prevention and control: a healthier future for girls and women. Switzerland: WHO Press; 2013. ISBN 9789241505147.

38. IARC. Cervix Cancer Screening. IARC Handbooks of Cancer Prevention: volume 10. Lyon: IARC Press; 2005. ISBN 9283230102.

\section{Acknowledgement}

This work was supported by Grant of Comenius University No. UK/117/2014.

Received: July,7,2014

Accepted: August,21,2014 